\title{
Risperidone oral disintegrating mini-tablets: A robust-product for pediatrics
}

\author{
KHALID M. EL-SAY $Y^{1,2}$ \\ TAREK A. AHMED ${ }^{1,2}$ \\ MAGED F. ABDELBARY ${ }^{3}$ \\ BAHAA E. ALI' ${ }^{2,4}$ \\ BADER M. ALJAEID ${ }^{1}$ \\ AHMED S. ZIDAN ${ }^{1,5^{*}}$ \\ ${ }^{1}$ Department of Pharmaceutics and \\ Industrial Pharmacy, Faculty of \\ Pharmacy, King Abdulaziz University \\ Jeddah, KSA \\ ${ }^{2}$ Department of Pharmaceutics and \\ Industrial Pharmacy, Faculty of \\ Pharmacy, Al-Azhar University, Cairo \\ Egypt \\ ${ }^{3}$ Research and Development \\ Department, Deef Pharmaceutical \\ Ind. Co., Qassim, KSA \\ ${ }^{4}$ Department of Pharmaceutics \\ College of Pharmacy, Salman Bin \\ Abdulaziz University, Alkharj, KSA \\ ${ }^{5}$ Department of Pharmaceutics and \\ Industrial Pharmacy, Faculty of \\ Pharmacy, Zagazig University \\ Zagazig, Egypt
}

Accepted July 23, 2015

\begin{abstract}
This study was aimed at developing risperidone oral disintegrating mini-tablets (OD-mini-tablets) as age-appropriate formulations and to assess their suitability for infants and pediatric use. An experimental Box-Behnken design was applied to assure high quality of the OD-mini-tablets and reduce product variability. The design was employed to understand the influence of the critical excipient combinations on the production of OD-mini-tablets and thus guarantee the feasibility of obtaining products with dosage form uniformity. The variables selected were mannitol percent in Avicel (X1), swelling pressure of the superdisintegrant (X2), and the surface area of Aerosil as a glidant (X3). Risperidone-excipient compatibilities were investigated using FTIR and the spectra did not display any interaction. Fifteen formulations were prepared and evaluated for preand post-compression characteristics. The prepared ODmini-tablet batches were also assessed for disintegration in simulated salivary fluid (SSF, pH 6.2) and in reconstituted skimmed milk. The optimized formula fulfilled the requirements for crushing strength of $5 \mathrm{kN}$ with minimal friability, disintegration times of 8.4 and $53.7 \mathrm{~s}$ in SSF and skimmed milk, respectively. This study therefore proposes the risperidone OD-mini-tablet formula having robust mechanical properties, uniform and precise dosing of medication with short disintegration time suitable for pediatric use.
\end{abstract}

Keywords: risperidone, mini-tablets, pediatrics, optimization design, disintegration

Mini-tablets incorporating orally disintegrating matrices (OD-mini-tablets) are mostly acceptable by infants and toddlers due to their potential easiness of administration, precise weight-based dosing, dose titration, fast-dissolution, fast-onset and improved bioavailability of drugs $(1,2)$. Mini-tablets can be recommended as multiple unit dosage forms that are equal or smaller than $3.0 \mathrm{~mm}$ in diameter. The manufacturing of OD-mini-tablets

\footnotetext{
*Correspondence; e-mail: aszidan@kau.edu.sa; azidoon@yahoo.com
} 
is highly affected by the properties of drug bulk excipients employed, like flowability and compressibility. Therefore, excipient combinations with excellent compaction properties should be preferably used. OD-mini-tablets can be filled into hard gelatin capsules to be administered with either suitable dosing devices or electronic dispensers that count automatically a variable number of doses $(2,3)$. Moreover, mini-tablets can be coated in a reproducible manner to require less coating material compared to regular tablets due to their smooth outer surface, constant specific surface area and robust mechanical characteristics (4). However, the production of mini-tablet formulations encountered uniformity problems. If the active ingredient is an extremely potent drug (microgram scale dosing or drug loading), a minimized range of specifications for mini-tablet mass and content variation would be recommended. The concept of »quality by design « $(\mathrm{QbD})$ is attracting great attention in pharmaceutical formulation development, stating that quality should not be tested in products, but should be instead built into a product. In this regard, the present study is aimed at using Box-Behnken optimization design to identify and minimize the critical sources of formulation and process variabilities encountered during the development of risperidone OD-mini-tablets for pediatric consumption.

Risperidone is an atypical and potent antipsychotic agent (the starting dosage of its commercial solution, Risperdal ${ }^{\circledR}$, is $0.25 \mathrm{mg}$ risperidone per day in children weighing less than $20 \mathrm{~kg}$, and $0.5 \mathrm{mg}$ risperidone per day in persons weighing at least $20 \mathrm{~kg}$ ). The drug is rapidly and completely absorbed upon its oral administration to achieve a terminal halflife of 20 hours (5). Risperidone powder has poor flowability and compaction properties due to its low bulk density, electrostatic charge, as well as sticking tendency. Consequently, the objective of this study was to incorporate risperidone in an OD matrix, followed by mini-tableting, using suitable excipient combinations not only to overcome its direct compression problems but also to be used for infants and toddlers ( $<2$ years of age). Hence, the feasibility of preparing risperidone OD-mini-tablets characterized by high drug load, robust mechanical properties and dosage uniformity was challenged in this study.

\section{EXPERIMENTAL}

Risperidone was supplied by Dr. Reddy's Laboratories Ltd. (India). Mannitol (USP32direct compressible grade) was supplied by Roquette (France). Microcrystalline cellulose (MCC, Avicel PH101) and croscarmellose sodium (Ac-Di-Sol) were supplied by FMC International Inc. (Ireland). Sodium starch glycolate (Explotab ${ }^{\circledR}$ ) was supplied by JRS (Germany). Plasdone XL100 was supplied by ISP (Switzerland). Colloidal silicon dioxides (Aerosil 200, 300, and 380) were supplied by Evonik (Germany). Aspartame was supplied by Dangschat $\mathrm{TOH} \mathrm{GmbH}$, (Germany) and peppermint oil was purchased from Daniel Inc. (UK). Other chemicals were of analytical grade and were used as received.

\section{Experimental design}

A three-level three-factor Box-Behnken experimental design was employed to statistically optimize the combination of excipients to prepare risperidone OD-mini-tablets with acceptable characteristics. The design space included the effects of three variables, namely mannitol percent in Avicel (X1), swelling pressure of the superdisintegrant (X2), and the surface area of Aerosil as a glidant (X3), on the investigated pre- and after-compression characteristics. Swelling pressure of the superdisintegrant could be defined by the pres- 
sure exerted in the outer direction or radial direction within the tablet. This could cause the tablet to burst or the absorption of water to be accelerated. Hence, an enormous increase in the volume of particles to promote disintegration could occur. Table I summarizes the independent variables and their levels studied to construct Box-Behnken combinations. These levels were determined based on our previous preliminary and screening studies. This design is suitable for exploring the quadratic response surfaces and the second order polynomial models and favors the optimization process at two-factor interaction effects of individual variables. For this purpose, 15 experimental runs were suggested (Table II). Construction of the model, analysis of the results and the optimization process were performed using JMP Software (Version 11.0.0, SAS institute Inc., Cary, NC, USA) to elucidate optimized risperidone OD-mini-tablet formulation.

Table I. Independent variables and their investigated levels in Box-Behnken design

\begin{tabular}{lccc}
\hline \multirow{2}{*}{ Variable } & \multicolumn{3}{c}{ Level } \\
\cline { 2 - 4 } & -1 & 0 & +1 \\
\hline Mannitol in Avicel (\%), X1 & 33.3 & 50 & 66.6 \\
Swelling pressure of the & Plasdone XL: & Explotab ${ }^{\circledR}:$ & Ac-Di-Sol: \\
superdisintegrant $(\mathrm{kPa}), \mathrm{X} 2$ & 94 & 158 & 271 \\
Surface area of the & Aerosil & Aerosil & Aerosil \\
glidant $\left(\mu \mathrm{m}^{2}\right), \mathrm{X} 3$ & 200 & 300 & 380
\end{tabular}

Table II. Composition of risperidone OD-mini-tablet formulations according to Box-Behnken design

\begin{tabular}{|c|c|c|c|c|c|c|c|c|c|c|c|c|c|c|c|}
\hline \multirow{2}{*}{ Ingredient } & \multicolumn{15}{|c|}{ Formulation } \\
\hline & $\mathrm{F} 1$ & F2 & F3 & $\mathrm{F} 4$ & F5 & F6 & F7 & F8 & F9 & F10 & F11 & F12 & F13 & F14 & F15 \\
\hline Avice & 2.6 & 2.6 & 1.3 & 1.3 & 1.45 & 1.45 & 1.3 & 1.3 & 2.6 & 2.6 & 1.45 & 1.45 & 1.45 & 1.45 & 1.45 \\
\hline Mannitol (mg) & 1.3 & 1.3 & 2.6 & 2.6 & 1.45 & 1.45 & 2.6 & 2.6 & 1.3 & 1.3 & 1.45 & 1.45 & 1.45 & 1.45 & 1.45 \\
\hline Ac-Di-Sol (mg) & - & - & 0.5 & - & - & 0.5 & - & - & 0.5 & - & - & 0.5 & - & - & - \\
\hline Plasdone (mg) & - & 0.5 & - & - & - & - & 0.5 & 0.5 & - & 0.5 & - & - & 0.5 & 0.5 & 0.5 \\
\hline Explotab $^{\circledR}(\mathrm{mg})$ & 0.5 & - & - & 0.5 & 0.5 & - & - & - & - & - & 0.5 & - & - & - & - \\
\hline Aerosil $200(\mu g)$ & - & - & - & - & - & 50 & 50 & - & - & 50 & 50 & - & - & - & - \\
\hline Aerosil $300(\mu g)$ & 50 & - & 50 & 50 & - & - & - & - & 50 & - & - & - & 50 & 50 & 50 \\
\hline Aerosil $380(\mu \mathrm{g})$ & - & 50 & - & - & 50 & - & - & 50 & - & - & - & 50 & - & - & - \\
\hline
\end{tabular}

a Each formula included $0.5 \mathrm{mg}$ risperidone, $25 \mu \mathrm{g}$ aspartame and $25 \mu \mathrm{g}$ peppermint oil.

\section{Drug-excipient compatibility}

Drug-excipient compatibilities were investigated using Fourier transform infrared spectroscopy (FTIR). FTIR spectra of both raw risperidone and its binary mixtures with 
tableting excipients were obtained using a $\mathrm{KBr}$ disk technique with a Perkin Elmer GX FTIR spectrophotometer (Parkin Elmer Inc., USA). Frequency range was between 400 and $4000 \mathrm{~cm}^{-1}$.

\section{Preparation of risperidone OD-mini-tablets}

Different risperidone OD-mini-tablets (Table II) were prepared by the direct compression technique. All ingredients were passed individually through a 40 mesh sieve $(0.425$ $\mathrm{mm})$, weighed and then mixed in geometrical order. Lubricant and glidant were finally added and mixed for further 5 min using a 3D blender (Model 5, Zhejiang Hualian, China) until a uniform mixture was obtained. After assessing the mixtures' flowability and density, they were compressed into 5-mg tablets using concave round punches under a constant compression force using Tablet-press II MT (Minipress, India).

\section{Evaluation of the powder blend}

The powder flow rate $\left(\mathrm{g} \mathrm{s}^{-1}\right)$ was determined using an Erweka Flow Tester (GDT, Germany) with a funnel of an internal diameter at the top of $6.5 \mathrm{~cm}$ and internal diameter of the efflux tube of $9 \mathrm{~mm}$. A 20-g sample was used and the powder flow time from inlet to outlet was recorded. The flow rate was determined as the ratio of mass (g) to time (s) in three determinations. The angle of repose $(\theta)$ was determined for each formula using a fixed hopper $(200 \mathrm{~mL})$ and a fixed base with a retaining lip to allow formation of a symmetric cone by the powder. The hopper was vibration free and was positioned at $4-\mathrm{cm}$ distance from the top of powder cone. The height and base of the powder cone were measured and the angle of repose was calculated.

\section{Evaluation of the prepared tablets}

The diameter and thickness of 10 tablets randomly selected from each formulation were determined using a Vernier caliper (L.S. Starrett Company, USA) and the mean $( \pm$ SD) of ten measurements were recorded. The digital image captured at $10 \times$ visual zooming depicts the prepared mini-tablets compared to the conventional tablet (Fig. 1). The radial crushing strength of the prepared OD-mini-tablets was determined using a texture analyzer (Stable Micro Systems, UK) and the speed of $0.05 \mathrm{~mm} \mathrm{~s}^{-1}$. Friability was determined by adding a constant mass (about $1 \mathrm{~g}$ ) of the mini-tablets into a snap-cap vial mechanically shaken at a frequency of $100 \mathrm{rpm}$ for 10 minutes. An air jet was then used to dedust the mini-tablets followed by their re-weighing to determine mass loss (2).

The uniformity of dosage units was demonstrated both by content uniformity and mass variation. According to the ICH guidelines the two tests were required because the prepared OD-mini-tablet mass was less than $25 \mathrm{mg}$ and contained drug substance less than $25 \%$ of their individual mass (6). The mass variation test was carried out by accurately weighing 20 tablets of each formula individually and calculating the average mass. Content uniformity testing was performed by selecting not fewer than 30 units and assaying 10 units individually for the initial drug content. For this purpose, each tablet was dissolved in $100 \mathrm{~mL}$ methanol in a volumetric flask. The dispersions were sonicated until complete dissolution and $1 \mathrm{~mL}$ of the solution was filtered, then assayed spectrophotometrically for its drug content at $280 \mathrm{~nm}$ (Lambda $25 \mathrm{UV}-\mathrm{VIS}$ spectrophotometer; Perkin 

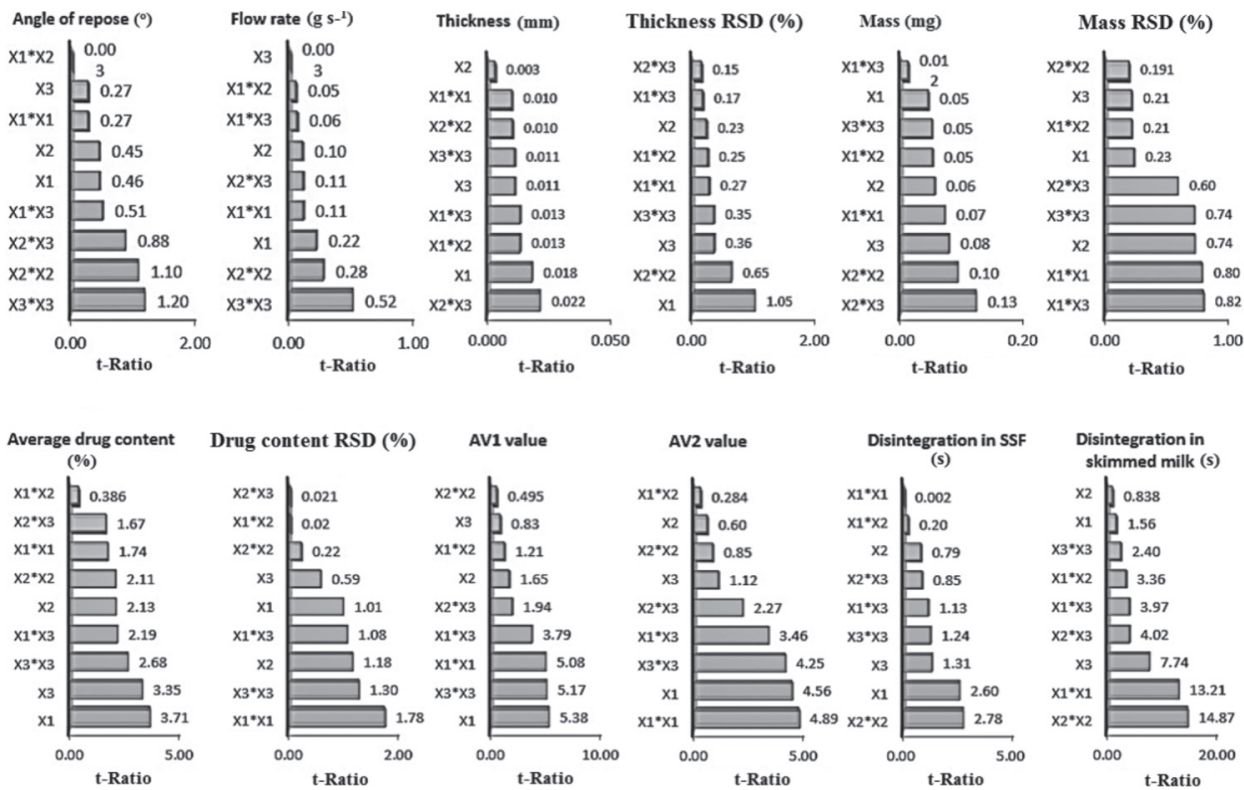

Fig. 1. Pareto charts showing the standardized effect of the investigated variables, their interaction and colinearities on the studied responses. AV1 and AV2 are the acceptance values of the first (AV1; $n=10, k=2.4$ ) and second (AV2; $n=30, k=2$ ) steps of content uniformity testing, respectively. $\mathrm{X} 1, \mathrm{X} 2$ and $\mathrm{X} 3$ are the percentage of mannitol as a diluent (\%), swelling pressure of the superdisintegrant $(\mathrm{kPa})$ and particle surface areas of the glidant $\left(\mu \mathrm{m}^{2}\right)$, respectively $(t$-ratio - degree of freedom for model error, estimated by dividing each parameter estimate by its standard error).

Elmer). The acceptance values (AV1 and AV2 for assaying 10 and 30 tablets, respectively) were calculated according to the following equation:

$$
\text { acceptance values }(\mathrm{AV})=\left[M-\mathrm{X}^{\prime}\right]+k s
$$

where $X^{\prime}$ is the mean of individual contents $(X 1, X 2, \ldots, X n), k$ is the acceptability constant (equal to 2.4 if $n=10$ and 2 if $n=30$ ), $M$ is the reference value and $s$ is the sample standard deviation.

The OD-mini-tablet disintegration was assessed using a modified disintegration method as described before (7). For this purpose, a Petri-dish containing $6 \mathrm{~mL}$ of simulated salivary fluid (SSF, $\mathrm{pH}$ 6.2) was used to mimic disintegration in human saliva. The SSF was composed of $\mathrm{KH}_{2} \mathrm{PO}_{4}\left(12 \mathrm{mmol} \mathrm{L}^{-1}\right), \mathrm{NaCl}\left(40 \mathrm{mmol} \mathrm{L}^{-1}\right), \mathrm{CaCl}_{2}\left(1.5 \mathrm{mmol} \mathrm{L}^{-1}\right)$, and $\mathrm{NaOH}$ to adjust the $\mathrm{pH}$ to 6.2 (8). A tissue paper was folded twice and kept wetted with SSF in the dish. A tablet was carefully placed in the center of the tissue and the time for complete disintegration into fine particles was noted. The experiment was also carried out using the reconstituted skimmed milk formula (Ronalac $1^{\circledR}$, Ronesca, France) as disintegration medium to mimic the disintegration conditions during nursing for pediatric applications. The major constituents of $100 \mathrm{~g}$ of the formula were $11.4 \mathrm{~g}$ protein, $26 \mathrm{~g}$ fats, $57.1 \mathrm{~g}$ dual carbohydrates (lactose and oligosaccharides) and $5.5 \mathrm{~g}$ minerals and vitamins. 


\section{RESULTS AND DISCUSSION}

\section{Flow properties of powder blends}

In the current study, the flow properties such as flow rate and angle of repose of 15 formulations within the Box-Behnken design were determined. Higher flow rate and lower angle of repose values would describe better flowability. The flow characteristics of powder blends for risperidone OD-mini-tablets are shown in Table III. It is worth noting that raw risperidone powder exhibited poor flow properties (data not shown) and was described as a cohesive powder with crystal flakes morphology (9). To improve its flow properties, tableting diluents with free-flowing, direct compression and swelling behavior were employed. Further, an attempt was made to achieve an easy-flowing property by mixing Avicel incorporating different percentages of mannitol (X1), different superdisintegrants with a range of swelling pressures $(X 2)$ and a glidant of different particle surface areas (X3) (Table II).

In the current investigation, angle of repose along with the powder flow rate were utilized to better describe the flow of powder blends. Table IV illustrates the regression results of flow parameters for 15 blends. All powder blends were smooth-surfaced and free flowing. Angle of repose for all formulations varied from 20.58 to $27.44^{\circ}$ with flow rates from 3.72 to $6.08 \mathrm{~g} \mathrm{~s}^{-1}$ to indicate the acceptable flow of most formulations (Table III). Individual and polynomial effects of the superdisintegrant and interaction effects of the glidant with either the diluent or the superdisintegrant were the significant factors affecting the resultant angle of repose. On the other hand, the polynomial action of the glidant surface area was the only variable that affected significantly the flow rates powders (Table IV and Fig. 1). Direct and negative relationships were observed between the swelling action of the superdisintegrant and the angle of repose and flow rate, respectively. Hence, the employed superdisintegrant of higher swelling pressure, namely Ac-Di-Sol, resulted in poor flow properties. On the other hand, Plasdone XL100, the superdisintegrant of the lowest swelling pressure, resulted in markedly better flow properties. This result could be explained by the different solid-state characteristics of the superdisintegrants (summarized in Table V). Ac-Di-Sol exhibited higher bulk and tapped densities with greater hydration capacity to impart a cohesive property to the powder blend. On the other hand, the lowest bulk and tapped densities of Plasdone XL100, along with its small particle size and low moisture contents, imparted better flow properties to the powder blends (Table V). Contour and surface plots in Fig. 2 showed the highest flow by employing superdisintegrant and glidant of medium values of swelling and surface area, respectively. Despite the non-significant negative effects of the glidant surface area on flow responses, this would suggest a synergistic effect of both factors at their middle values compared to their extremes. In addition, despite being a non-significant variable, the increasing mass percentage of free-flowing mannitol in Avicel as a combined filler further increased the flow of tableting blends. In general, the variation of flow parameters could be attributed to the variation in the frictional and attractive forces among the incorporated particles of different shapes, sizes, densities and surface roughness.

One of the important advantages of the multiple regression models is their ability to predict the value of each response based on the values of the investigated variables within the design space. Examining the developed regression analysis equations for flow re- 


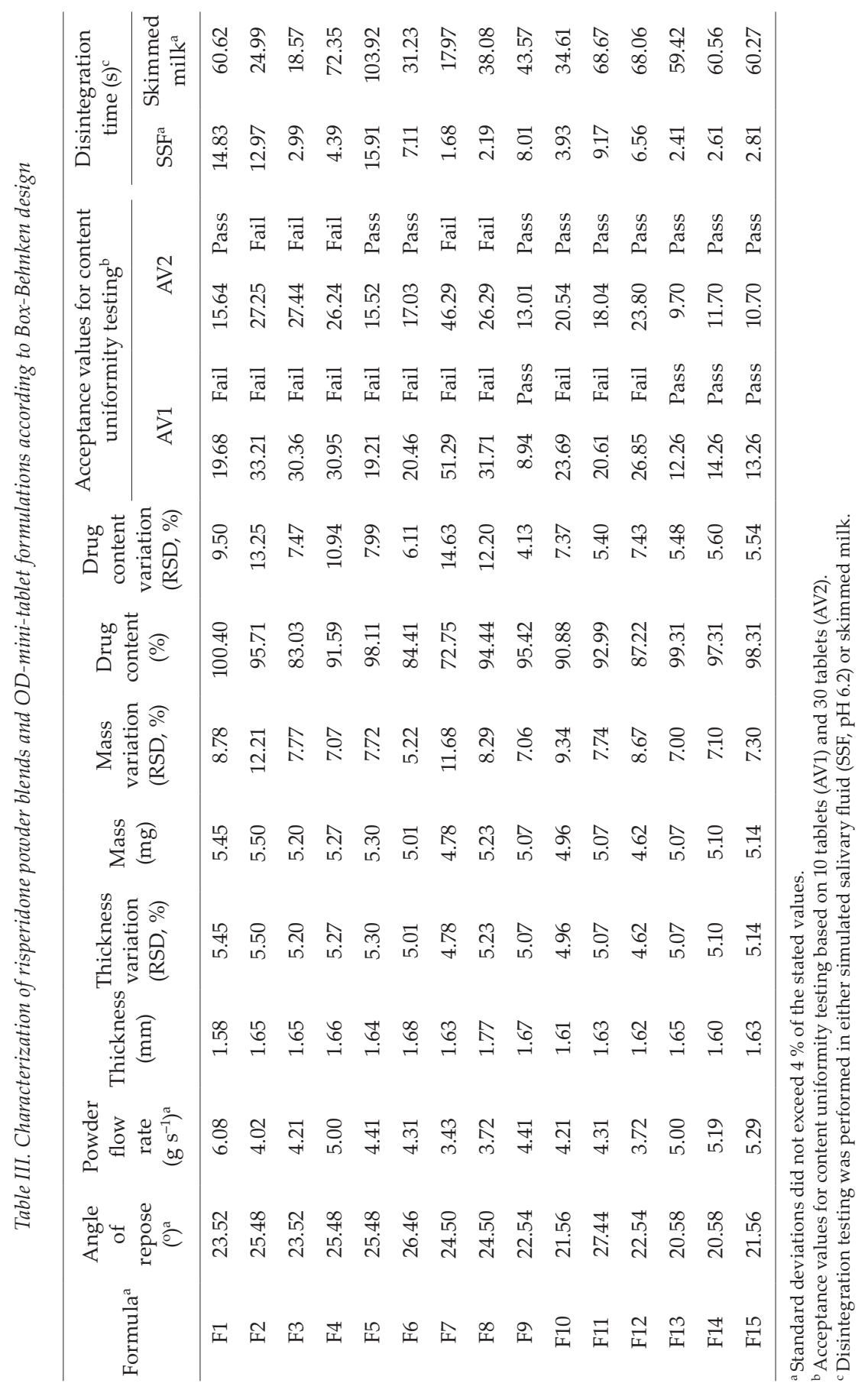




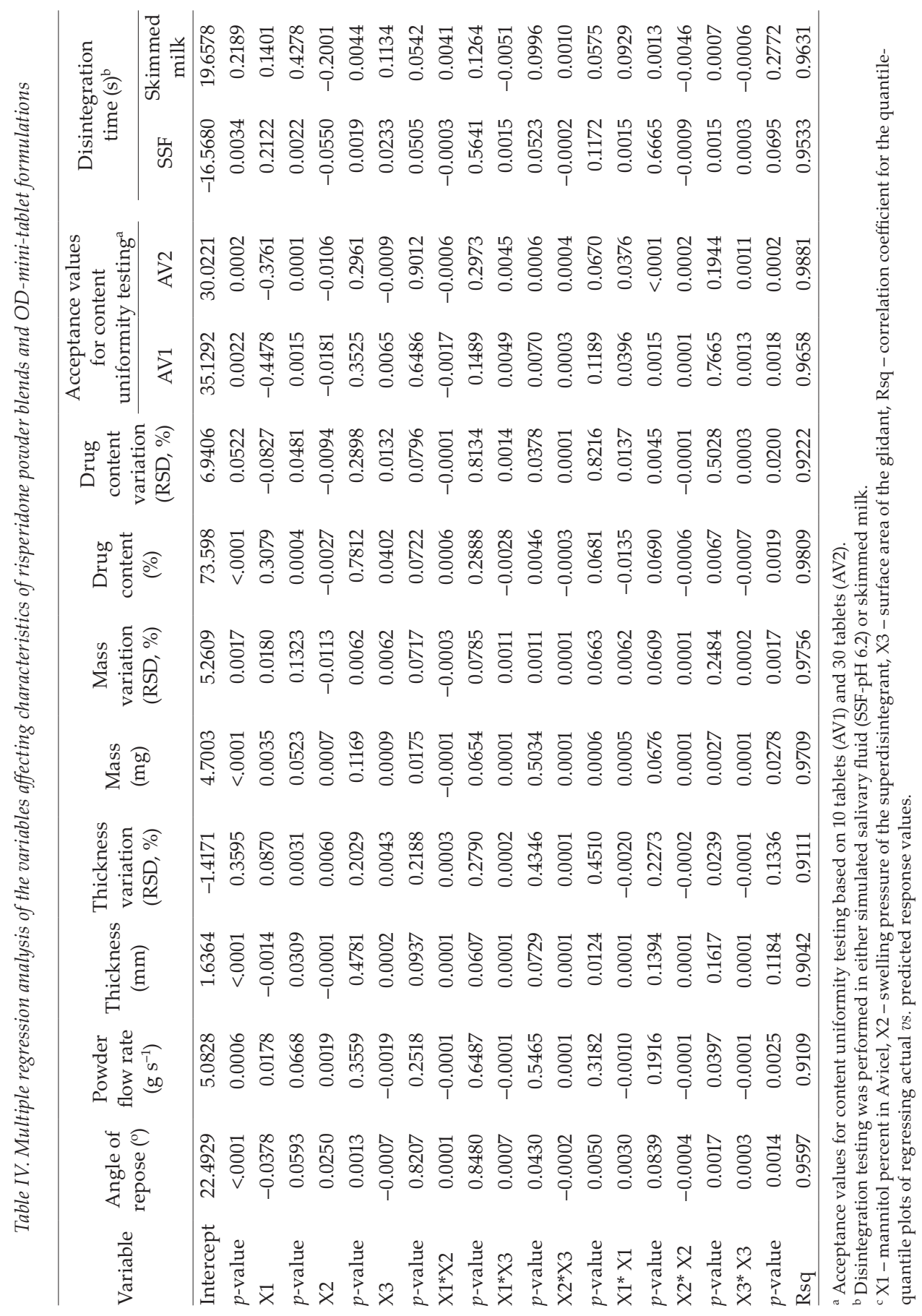


Table V. Solid-state characteristics of the employed superdisintegrants

\begin{tabular}{lcccccccc}
\hline $\begin{array}{l}\text { Super- } \\
\text { disintegrant }\end{array}$ & $\begin{array}{c}\text { Bulk } \\
\text { density } \\
\left(\mathrm{g} \mathrm{mL}^{-1}\right)\end{array}$ & $\begin{array}{c}\text { Tapped } \\
\text { density } \\
\left(\mathrm{g} \mathrm{mL}^{-1}\right)\end{array}$ & $\begin{array}{c}\text { Particle } \\
\text { size } \\
(\mu \mathrm{m})\end{array}$ & $\begin{array}{c}\text { Span } \\
\text { contents } \\
(\%)^{\mathrm{a}}\end{array}$ & $\begin{array}{c}\text { Swelling } \\
\text { pressure } \\
(\mathrm{kPa})\end{array}$ & $\begin{array}{c}\text { Time to } \\
\text { maximum } \\
\text { swelling }(\mathrm{s})\end{array}$ & $\begin{array}{c}\text { Swelling } \\
\text { volume } \\
\left(\mathrm{L} \mathrm{kg}^{-1}\right)\end{array}$ & $\begin{array}{c}\text { Hydration } \\
\text { capacity } \\
(\mathrm{m} / \mathrm{m})^{\mathrm{b}}\end{array}$ \\
\hline Ac-Di-Sol & 0.46 & 0.72 & 49 & 2.4 & 271 & 88.1 & 13.5 & 12.1 \\
Plasdone XL100 & 0.33 & 0.48 & 27 & 1.8 & 94 & 85.4 & 5.4 & 4.6 \\
Explotab $^{\circledR}$ & 0.76 & 0.92 & 41 & 1.1 & 158 & 75.2 & 23.6 & 18.3 \\
\hline
\end{tabular}

${ }^{a}$ Loading of surfactant in superdisintegrant.

${ }^{\mathrm{b}}$ Moisture absorption capacity per unit mass of superdisintegrant.
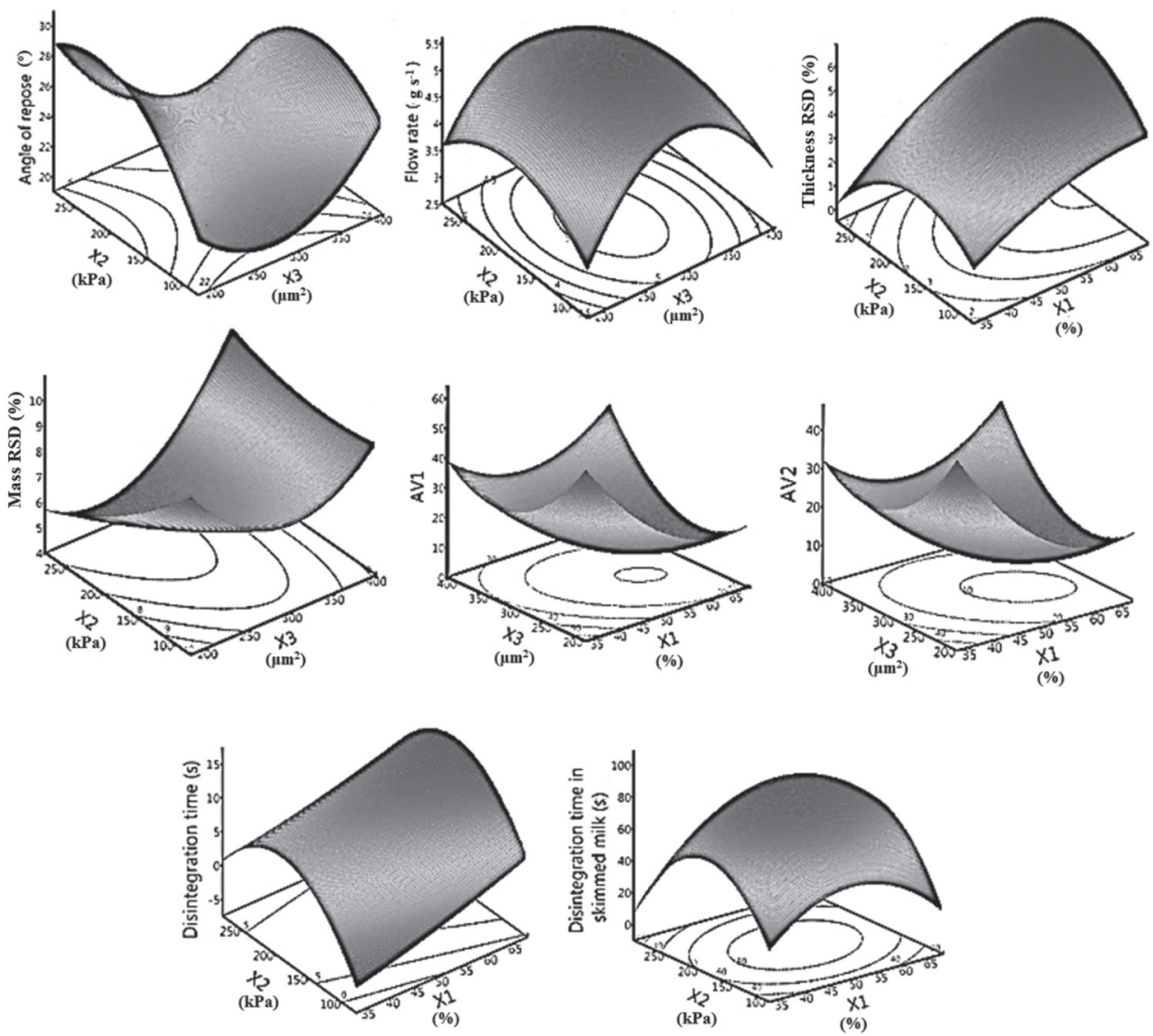

Fig. 2. Response surface (3D) and contour plots showing the standardized effect of the investigated variables on the studied responses. AV1 and AV2 are the acceptance values of the first (AV1; $n=10$, $k=2.4$ ) and second (AV2; $n=30, k=2$ ) steps of content uniformity testing, respectively. X1, X2 and X3 are the percentage of mannitol as a diluent (\%), swelling pressure of the superdisintegrant $(\mathrm{kPa})$ and particle surface areas of the glidant $\left(\mu \mathrm{m}^{2}\right)$, respectively. 
sponses revealed good predictabilities with $p=0.0055$ and 0.0351 for the angle of repose and flow rate with quantile-quantile correlation coefficients of 0.9597 and 0.9109 , respectively. The linear reduced model equations to predict both responses are given below:

$$
\begin{aligned}
& \text { angle of repose }\left({ }^{\circ}\right)=22.4+0.02 * X 2-0.00007 * X 3-0.03 * X 1 \\
& +(X 2-158.2) *((X 3-294.6) *-0.0001)+(X 2-158.2) *((X 1-49.9) *-0.00004) \\
& +(X 3-294.6) *((X 1-49.97) *-0.0006)+(X 2-158.2) *((X 2-158.2) *-0.0003) \\
& +(X 3-294.6) *((X 3-294.6) *-0.0003)+(X 1-49.97) *((X 1-49.97) *-0.0029) \\
& \text { flow rate }\left(g^{-1}\right)=5.08+0.001 * X 2-0.001 * X 3-0.01 * X 1 \\
& +(X 2-158.2) *((X 3-294.6) *-0.00002)+(X 2-158.2) *((X 1-49.97) *-0.00005) \\
& +(X 2-158.2) *((X 2-158.2) *-0.00008)+(X 3-294.6) *((X 1-49.97) *-0.00007) \\
& +(X 3-294.6) *((X 3-294.6) *-0.00013)+(X 1-49.97) *((X 1-49.97) *-0.00101)
\end{aligned}
$$

\section{Formulation of risperidone loaded OD-mini-tablets}

All 15 formulae of the Box-Behnken design could be compressed into 2-mm diameter mini-tablets with the average crushing strength over $5 \mathrm{kN}$. Most formulations were slightly friable; however, the friability results could not correlate with those from the crushing strength testing. For friable OD-mini-tablets, application of higher compression forces was required to achieve a crushing strength of about $5 \mathrm{kN}$. After this pretreatment, all the prepared mini-tablets were well formed with no signs of abrasion, damage, capping or lamination. Fig. 3 shows digital images of the prepared OD-mini-tablets loaded with 0.5 mg risperidone (formula F9), a single daily dose for infants weighing less than $15 \mathrm{~kg}(10)$. The figure illustrates the mini-tablet size in comparison with a dosing spoon with 2.5 and $5 \mathrm{~mL}$ capacity and adult oral risperidone tablets to simulate the dosing of risperidone solution $\left(0.1 \mathrm{mg} \mathrm{kg}^{-1}\right.$ adult body mass).

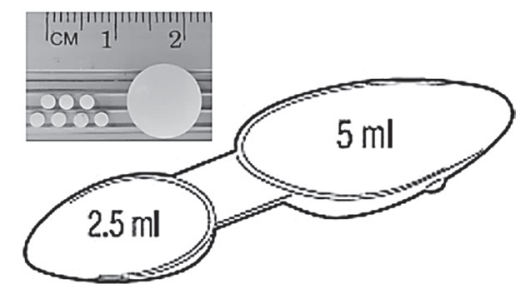

Fig. 3. Seven orally disintegrating mini-tablets (formula F9) with $0.5 \mathrm{mg}$ risperidone loading per minitablet in comparison with an oral adult risperidone tablet and a dosing spoon with 2.5 and $5 \mathrm{~mL}$ capacity.

\section{Thickness uniformity}

The thickness values for the OD-mini-tablets of different formulations are shown in Table III. Based on the experiments, all the OD-mini-tablet thickness ranged from 1.58 (formula F1) to $1.77 \mathrm{~mm}$ (formula F8) with respective RSDs from $4.6 \%$ (formula F12) to $5.5 \%$ 
(formula F2). Regression analysis results revealed that both the individual effect of mannitol percentage in the employed diluent (X1) and the interaction effect of the superdisintegrant swelling pressure and the glidant surface area $\left(X 2^{*} \mathrm{X} 3\right)$ were the significant factors that affected the resultant thickness. On the other hand, $\mathrm{X} 1$ and $\mathrm{X} 2{ }^{*} \mathrm{X} 2$ were significant for their influence on thickness variability (Table IV and Figure 1). Mannitol-to-Avicel $(\mathrm{m} / \mathrm{m})$ ratio was found to have both inverse and direct effects on the resultant thickness and thickness variability. This might be attributed to the fact that increasing mannitol percentage led to decreasing Avicel loading within the powder blend. During compression, the large surface area of Avicel particles come into close contact to facilitate hydrogen bond formation. Increasing mannitol loading would potentiate this hydrogen bonding affinity by its hydroxyl groups among the plastically deformed cellulose particles to decrease the resultant thickness with greater variability (Fig. 2). On the other hand, at both lowest and highest levels of mannitol, increasing the swelling pressure of the superdisintegrant resulted in an increase in the resultant thickness. The effect of the superdisintegrant of increasing moisture within the porous structure of Avicel to act as an internal lubricant would explain its effects on both responses. This facilitated the slippage and flow within individual microcrystals during plastic deformation to enforce the formation of hydrogen bond bridges (11).

The predictability of thickness by the model was acceptable $(p=0.0413)$ with a coefficient of determination $\left(R^{2}\right)$ of 0.9042 for plotting the predicted thickness versus experimental values. After neglecting insignificant variables, the reduced linear model equation, which explains the effect of only significant variables on OD-mini-tablet thickness, can be expressed as:

OD-mini-tablets' thickness $(\mathrm{mm})=1.63-0.0014 * \mathrm{X} 1+(\mathrm{X} 2-158.2) *\left((\mathrm{X} 3-294.6){ }^{*}-0.000004\right)$

OD-mini-tablets' thickness deviation $(\mathrm{RSD}, \%)=-1.41-0.08 * \mathrm{X} 1$

$$
+(\mathrm{X} 2-158.2) *((\mathrm{X} 2-158.2) *-0.00019)
$$

\section{Mass uniformity}

Average masses along with the respective RSDs for the OD-mini-tablets of different formulations are shown in Table III. All the average OD-mini-tablet masses were in the range of $4.62 \mathrm{mg}$ (formula F12) to $5.5 \mathrm{mg}$ (formula F2) with RSD of $5.2 \%$ (formula F6) to 12.2 $\%$ (formula F2). The obtained results showed an inverse second-order relationship between the mass deviation and flow rate of the powder blend for each formulation (Fig. 4). Hence, better flow of the powder blend through the small die orifice led to uniform filling and subsequently acceptable mass uniformity (12). The obtained regression results revealed that both the individual effect of the glidant surface area (X3) and the interaction effect of the superdisintegrant swelling pressure and the glidant surface area $\left(X 2^{*} X 3\right)$ were significant variables affecting OD-mini-tablet mass. On the other hand, $\mathrm{X} 2, \mathrm{X} 1^{*} \mathrm{X} 3$ and $\mathrm{X} 3^{*} \mathrm{X} 3$ were significant for their effects on mass deviation (Table IV and Fig. 1). Although the small particle size of the glidant could be an advantage for flowability through a small orifice, mass uniformity problems may occur (Fig. 2). The possible explanation for this observation would be the granule growth and segregation that could occur during the compaction process resulting in a deviation from average mass of mini-tablets. At higher surface area of the glidant, increasing the swelling pressure of the superdisintegrant was accompanied 

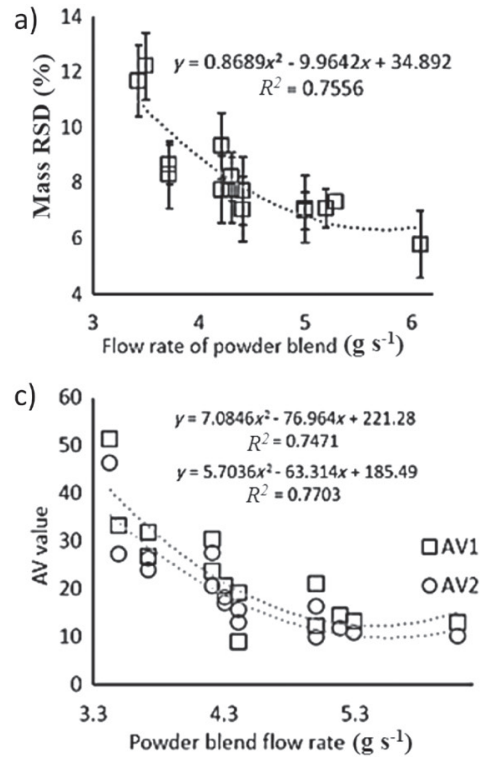

b)

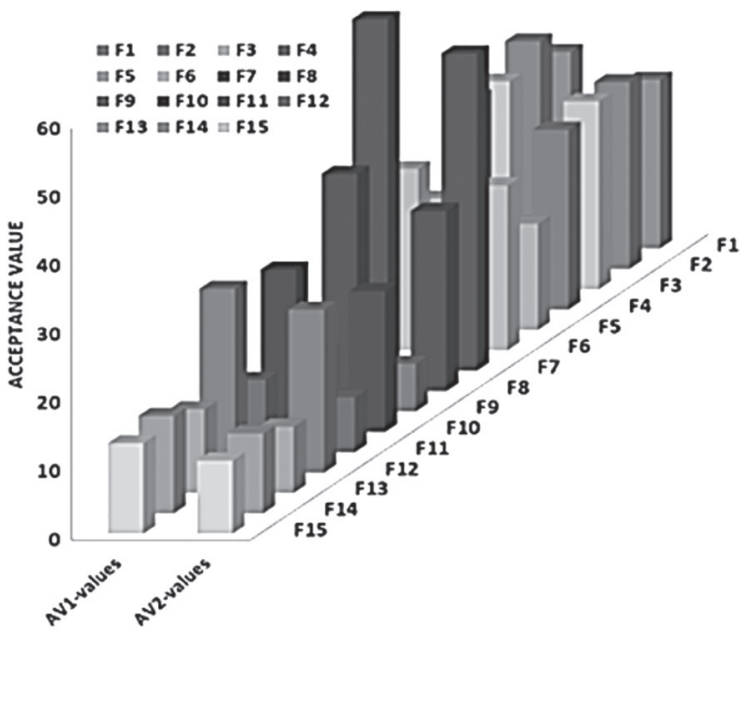

Fig. 4. a) Mass deviation of risperidone loaded OD-mini-tablets expressed as a relative standard deviation as the function of the flow rate of the powder blend. b) Distribution of acceptance values of the first (AV1; $n=10, k=2.4$ ) and second (AV2; $n=30, k=2$ ) steps of content uniformity test for the 15 OD-mini-tablets formulations. c) Acceptance values as the function of the flow rate of the powder blend. Standard deviations of the powder flow rates did not exceed $4 \%$ of the stated values.

by a non-significant decrease in the mini-tablet mass and consequently an increase in mass variation. Influences of the investigated superdisintegrants on bulk and tapped densities of the powder blends and subsequently the resultant flow properties (Table V) could explain this result. The superdisintegrant of higher swelling pressure, namely Ac-Di-Sol, was associated with poor flow properties and higher mass variation. On the other hand, Plasdone XL100, the superdisintegrant of the lowest swelling pressure, was associated with better flow and the least mass variation. Hence, the interaction between X2 and X3 had considerable importance in controling both the flow characteristics and dosage unit variability. For both responses, it was also worth noting that the effect of diluent composition was minimal and non-significant.

The constructed model showed good predictabilities of $p=0.0025$ and 0.0016 for minitablet mass and mass deviation with quantile-quantile correlation coefficients of 0.9709 and 0.9756 , respectively. The linear reduced model equations for predicting both responses are:

$$
\begin{aligned}
& \text { OD-mini-tablet mass }(\mathrm{mg})=4.7-0.0009 * \mathrm{X} 3+(\mathrm{X} 2-158.2) *((\mathrm{X} 3-294.6) *-0.00002) \\
& +(\mathrm{X} 2-158.2) *((\mathrm{X} 2-158.2) *-0.00002)+(\mathrm{X} 3-294.6) *((\mathrm{X} 3-294.6) *-0.00001) \\
& \text { OD-mini-tablet mass deviation }(\mathrm{RSD}, \%)=5.2-0.01 * \mathrm{X} 2 \\
& +(\mathrm{X} 2-158.2) *((\mathrm{X} 3-294.6) *-0.00011)+(X 3-294.6) *((X 3-294.6) *-0.00018)
\end{aligned}
$$




\section{Drug content uniformity}

With a risperidone content of only $0.5 \mathrm{mg}$ per unit, the investigated OD-mini-tablets best fit to low-dose dosage forms. Results of the analysis of risperidone content and its variation (RSD, \%) are given in Table III. Distributions of the acceptance values of the first (AV1; $n=10, k=2.4$ ) and second (AV2; $n=30, k=2)$ step are also shown in Table III and Fig. $4 \mathrm{~b}$. The determined average risperidone contents, expressed as percentage of the label claim varied between $72.8 \%$ (formula F7) and $100.4 \%$ (formula F1), in 10 units of the produced OD-mini-tablets. The distributions of all OD-mini-tablet formulations showed high skewness and kurtosis for AV1 values, which decreased for AV2 values and could be well approximated to a log normal distribution (Fig. 4b). Table III shows that only formulations F9, F13, F14 and F15 could pass the first step of the content uniformity test with AV1 below 15. On the other hand, formulations F2, F3, F4, F7 and F8 could not pass the second step of the content uniformity test with AV2 below 25.

The obtained regression results in Table IV and Fig. 2 reveal that both the individual and polynomial effects of mannitol concentration (X1) and its interaction with the glidant surface area $\left(X 1^{*} X 3\right)$, in addition to the polynomial effect of the glidant surface area $\left(X 3^{*} X 3\right)$, were significant variables affecting average risperidone content. These variables were also significant for the corresponding deviations of AV1 and AV2 values for the prepared ODmini-tablets. The individual effect of X1 was positive for the average drug content and negative for drug content deviations, AV1 and AV2. On the other hand, the influence of $\mathrm{X} 1^{*} \mathrm{X} 1, \mathrm{X} 1^{*} \mathrm{X} 3$ and $\mathrm{X} 3^{*} \mathrm{X} 3$ was negative for the average drug content and positive for drug content deviations AV1 and AV2 (Table IV). The influence of the flow properties of powder blends on both the first and second step acceptance values was recognized (Fig. 4c). Increasing the flow properties decreased AV1 and AV2 in polynomial relationships, explaining the role of mannitol in increasing the flowability of powder blends. As expressed by the relative surface area, the variation between the co-processed excipient particle sizes and risperidone powder could lead to slight segregation of the powder mixtures. This phenomenon could explain the role of the glidant surface area in increasing the acceptance values, hence deteriorating the resultant content uniformity. Fair predictability of AV1 and AV2 by the model (AV1: $p=0.0061$ and $R^{2}=0.9176$; whereas AV2: $p=0.0001$ and $R^{2}=0.9384$ ) was possible according to the following reduced equations:

$$
\begin{gathered}
\mathrm{AV} 1=35.1-0.44 * X 1+(\mathrm{X} 1-49.97) *((\mathrm{X} 3-294.6) * 0.0048) \\
+(\mathrm{X} 1-49.9) *((\mathrm{X} 1-49.97) * 0.0396)+(X 3-294.6) *((X 3-294.6) * 0.0013) \\
\mathrm{AV} 2=30.02-0.37 * X 1+(X 1-49.97) *((X 3-294.6) * 0.00446) \\
+(\mathrm{X} 1-49.97) *((X 1-49.97) * 0.03760)+(X 3-294.6) *((X 3-294.6) * 0.00107)
\end{gathered}
$$

\section{OD-mini-tablet disintegration}

Disintegration time of the prepared OD-mini-tablets was tested in both SSF and skimmed milk formula (Table III). Longer disintegration times were observed in skimmed milk in comparison with those in SSF. Compared to that of SSF, this result was expected due to higher viscosity and density of the milk formula that might retard the swelling action of the superdisintegrant in facilitating OD-mini-tablets disintegration. As reported in 
previous studies, milk analysis revealed Newtonian rheological properties with the coefficient of viscosity of $2.1 \mathrm{mPa} \mathrm{s}^{-1}$ under moderate shear rates $\left(>10 \mathrm{~s}^{-1}\right)$ at $20{ }^{\circ} \mathrm{C}$ when fat contents are below $40 \%$ (13). Moreover, depending on its fat, protein and other ingredients, as well as the working temperature, milk density ranged between 1.028 and $1.038 \mathrm{~g} \mathrm{~mL}$ (14). On the other hand, SSF exhibited non-Newtonian behavior with the coefficient of viscosity of $0.015-0.002 \mathrm{mPa} \mathrm{s}^{-1}$ at shear rates of $0.5-94.5 \mathrm{~s}^{-1}$ (15). All OD-mini-tablet disintegration times were in the range from 1.68 and $17.97 \mathrm{~s}$ (formula F7) to 15.91 and $103.92 \mathrm{~s}$ (formula F5) in SSF and skimmed milk formula, respectively. All the prepared OD-mini-tablets complied with the FDA rules (2) for disintegration in SSF, indicating it their suitability for disintegration in the infant's mouth. Disintegration times in skimmed milk were higher but still suitable for disintegration in feeding bottles.

Results of the multiple regression analysis showed inverse significant effects of the swelling pressure of the superdisintegrant, either individually or combined, on the disintegration time in both media (Table IV and Figs. 1 and 2). In addition, a direct and significant effect of mannitol as a diluent was also observed, which was individually and collinearly related to disintegration in SSF and skimmed milk, respectively. The action of superdisintegrants of decreasing the disintegration time can be explained by their physical characteristics listed in Table V. Higher swelling pressure was achieved by employing Ac-Di-Sol ${ }^{\circledR}$, which exhibited the longest time for maximum swelling. The lowest swelling pressure of Plasdone ${ }^{\circledR}$ XL100 was associated with the lowest swelling volume and hydration capacity. Hence, the shortest disintegration times in both media were attained by employing Explotab ${ }^{\circledR}$, which showed medium swelling pressure, shortest time for maximum disintegration, greatest swelling volume and highest hydration capacity. In comparison to other superdisintegrants, similar results were recorded by Pabari and co-workers (16) described the most efficient disintegration action of Explotab ${ }^{\circledR}$ owing to its highest water absorption ratio, rapid rate of water uptake and enhanced wetting of the tablets as a result of its porous structure. On the other hand, Juppo (17) explained the longer disintegration times with increasing mannitol loading within the OD-mini-tablets by its action on the overall tablet porosity. The same author found that mannitol tablets were the strongest, with greater breaking strength and expected longer disintegration even in case of high total pore volume. The developed prediction model showed good predictabilities with $p=0.0078$ and 0.0044 for disintegration times in SSF and skimmed milk, with quantile-quantile coefficients of determination of 0.9533 and 0.9631 , respectively. The linear reduced model equations for predicting both responses are given below:

$$
\begin{gathered}
\text { disintergration time in SSF }(\mathrm{s})=-16.5+0.21 * \mathrm{X} 1-0.05 * \mathrm{X} 2 \\
+(\mathrm{X} 2-158.2) *((\mathrm{X} 2-158.2) *-0.0008)
\end{gathered}
$$

disintergration time in skimmed milk $(\mathrm{s})=19.6+0.14 * \mathrm{X} 1-0.20 * \mathrm{X} 2$

$$
+(\mathrm{X} 2-158.2) *((\mathrm{X} 2-158.2) *-0.0046)
$$

\section{Optimization by generalized desirability function}

For each response, the individualized desirability was set its 'importance' that could vary the response. The options for individualized desirabilities were maximizing, minimizing or match target value (Table VI). The obtained results showed that OD-mini-tablet 
Table VI. Optimization of individual responses to apply a generalized desirability function

\begin{tabular}{|c|c|c|c|c|c|c|c|}
\hline \multicolumn{2}{|l|}{ Response } & Goal & $\begin{array}{l}\text { Lower } \\
\text { limit }\end{array}$ & $\begin{array}{l}\text { Upper } \\
\text { limit }\end{array}$ & $\begin{array}{l}\text { Lower } \\
\text { mass }\end{array}$ & $\begin{array}{l}\text { Upper } \\
\text { mass }\end{array}$ & $\begin{array}{l}\text { Import- } \\
\text { ance }\end{array}$ \\
\hline \multicolumn{2}{|c|}{ Angle of repose $\left(^{\circ}\right)$} & Minimize & 20 & 29 & 0.9819 & 0.066 & 0.08 \\
\hline \multicolumn{2}{|c|}{ Powder flow rate $\left(\mathrm{g} \mathrm{s}^{-1}\right)$} & Maximize & 3 & 6.5 & 0.066 & 0.9819 & 1 \\
\hline \multicolumn{2}{|l|}{ Thickness (mm) } & $\begin{array}{l}\text { Match target } \\
\text { to } 1.675 \mathrm{~mm}\end{array}$ & 1.575 & 1.775 & 0.0183 & 0.0183 & 1 \\
\hline \multicolumn{2}{|c|}{ Thickness variation (RSD, \%) } & Minimize & 0 & 5 & 0.9819 & 0.066 & 1 \\
\hline \multicolumn{2}{|l|}{ Mass (mg) } & $\begin{array}{l}\text { Match target } \\
\text { to } 5 \mathrm{mg}\end{array}$ & 4.6 & 5.6 & 0.0183 & 0.0183 & 1 \\
\hline \multicolumn{2}{|c|}{ Mass variation (RSD, \%) } & Minimize & 0 & 5 & 0.9819 & 0.066 & 1 \\
\hline \multirow{4}{*}{$\begin{array}{l}\text { Content } \\
\text { uniformity }\end{array}$} & Drug content (\%) & $\begin{array}{l}\text { Match target } \\
\text { to } 100 \%\end{array}$ & 95 & 105 & 0.0183 & 0.0183 & 1 \\
\hline & $\begin{array}{l}\text { Drug content } \\
\text { variation (RSD, \%) }\end{array}$ & Minimize & 0 & 5 & 0.9819 & 0.066 & 1 \\
\hline & $\mathrm{AV}^{\mathrm{a}}$ & Minimize & 0 & 14 & 0.9819 & 0.066 & 0.75 \\
\hline & $\mathrm{AV}^{\mathrm{a}}$ & Minimize & 0 & 24 & 0.9819 & 0.066 & 0.75 \\
\hline \multirow{2}{*}{$\begin{array}{l}\text { Disintegration } \\
\text { time }(\mathrm{s})^{\mathrm{b}}\end{array}$} & SSF & Minimize & 0 & 17.5 & 0.9819 & 0.066 & 1 \\
\hline & Skimmed milk & Minimize & 10 & 110 & 0.9819 & 0.066 & 1 \\
\hline
\end{tabular}

a Acceptance values for content uniformity testing based on 10 tablets (AV1) and 30 tablets (AV2).

${ }^{\mathrm{b}}$ Disintegration testing was performed in either simulated salivary fluid (SSF, pH 6.2) or skimmed milk.

characteristics were significantly affected by the angle of repose and flow rate of powder blend. Therefore the individualized desirabilities for both responses was set to 'minimize' and 'maximize', respectively, with the corresponding 'importance' of 1 to indicate their highest priorities. As constant thickness with minimal variation is usually required not only to assure the quality of the prepared products but also to fit its unique application through a tablet dispenser, 'match target to $1.675 \mathrm{~mm}^{\prime}$ and 'minimize' goals were selected for both responses, respectively, with the 'importance' of the 1. OD-mini-tablet mass is critical in ensuring the required dose of risperidone; hence, the goals for the average mass and its deviation were selected as 'match target to $5 \mathrm{mg}^{\prime}$ and 'minimize', respectively, with the highest priority of importance. To pass the content uniformity testing, the goals for the AV1 and AV2 values were assigned as 'minimize' with the 0.75 importance. The shortest disintegration times are important to ensure the applicability of the product to the pediatric patients and nursing mothers; hence, 'minimize' goals were selected for the disintegration times in both SSF and skimmed milk formula with the importance of 1 . The lower and upper limit values of all the investigated responses were driven from the Box-Behnken design levels (Table VI) and the optimization process was performed under these conditions.Through this desirability function, the predicted values of the angle of repose, powder flow rate, thickness and its deviation percent, mass and its deviation percent, drug content and its deviation percent, AV1, AV2, and disintegration times in SSF and skimmed milk formula were $24.6^{\circ}, 5.09 \mathrm{~g} \mathrm{~s}^{-1}, 1.66 \mathrm{~mm}, 4.1 \%, 5.1 \mathrm{mg}, 3 \%, 98 \%, 3.5 \%, 7.5,8.1,8.4$ and $53.7 \mathrm{~s}$, respectively, at X1, X2 and X3 levels of $60.5 \%, 255 \mathrm{kPa}$ and $245 \mu \mathrm{m}^{2}$, respectively. To 
further validate the prediction model, a confirmatory experiment was performed using the proposed optimized formulation having $60 \%$ mannitol, $40 \%$ Avicel, Ac-Di-Sol as the superdisintegrant and a mixture of Aerosil 200 and Aerosil $300(1: 1, \mathrm{~m} / \mathrm{m})$ as glidant mixture. The obtained responses were significantly close $(p<0.05)$ to the values predicted by the desirability function with standard errors not higher than $4 \%$ of each value.

\section{Compatibility studies}

Typical interaction spectra by FTIR analysis are shown in Fig. 5 and refer to raw risperidone powder and its 1:1 $(\mathrm{m} / \mathrm{m})$ binary mixtures with the investigated diluents, glidants or superdisintegrants. The spectrum of raw risperidone powder shows a weak band of $\mathrm{C}-\mathrm{H}$ stretching of the aromatic ring at $3065 \mathrm{~cm}^{-1}$. A strong band of $\mathrm{C}=\mathrm{O}$ stretching of the $\delta$-lactam ring is shown at $1641 \mathrm{~cm}^{-1}$. The medium intensity bands of $\mathrm{C}=\mathrm{C}$ stretching of the aromatic ring and region A corresponding to $\mathrm{C}-\mathrm{N}$ and $\mathrm{C}-\mathrm{O}$ angular deformations of the oxazole ring can be observed at 1613 and $1535 \mathrm{~cm}^{-1}$, respectively. On the other hand, the intermediate band of C-N stretching of the oxazole ring can be seen at $1350 \mathrm{~cm}^{-1}$. The weak stretch of the tertiary amine of the piperidine ring is shown at $1190 \mathrm{~cm}^{-1}$. In addition, the strong peak that is observed at $1129 \mathrm{~cm}^{-1}$ corresponds to aryl fluoride (9).

Comparing FTIR spectra of the raw drug and its binary mixtures, some variations in the absorption bands were observed, especially in the risperidone fingerprint region (600 to $1800 \mathrm{~cm}^{-1}$ ). In particular, in the mixtures with Avicel and mannitol, there is a reduction in the intensity of most stretches in addition to slight changes in the shapes of the absorp-

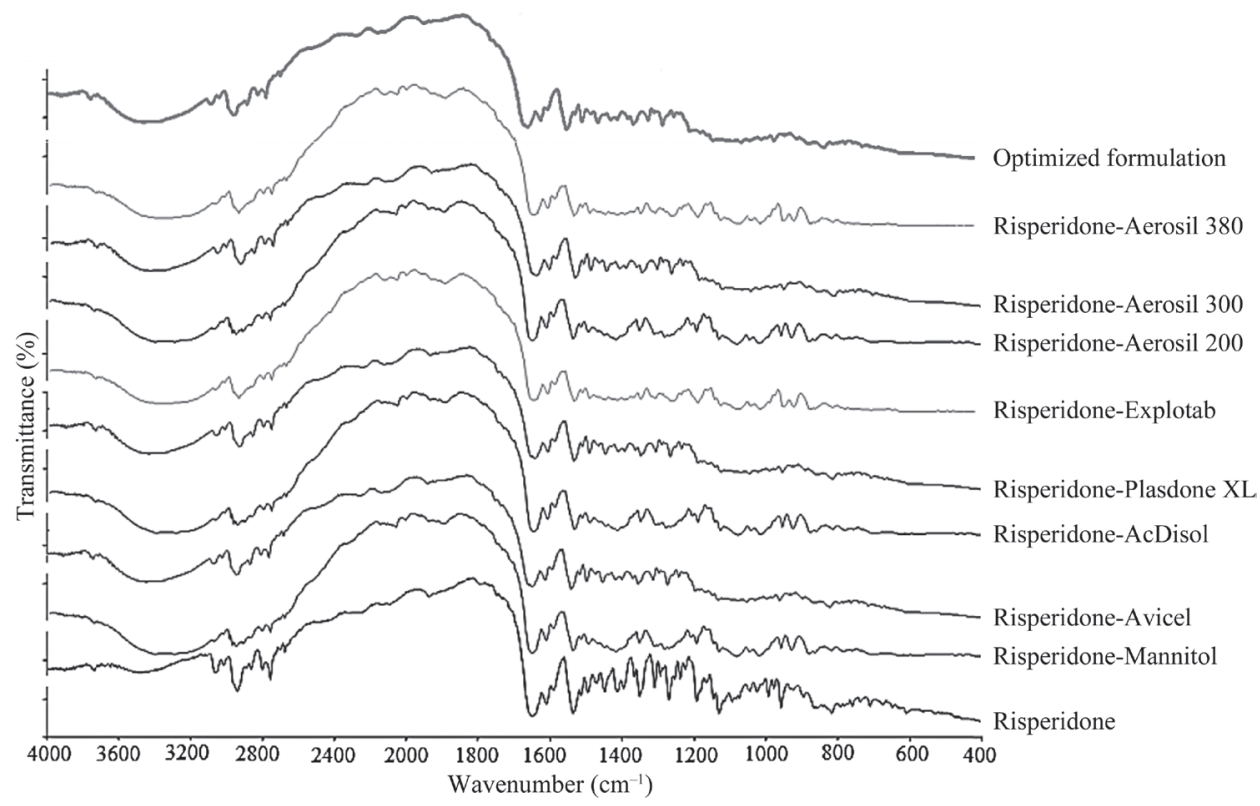

Fig. 5. FTIR spectra of risperidone raw powder, its binary mixtures with the investigated diluents, superdisintegrants and glidants and the optimized formulation. 
tion peaks in the region of 1000 and $1250 \mathrm{~cm}^{-1}$. In the mixture with Aerosil and Explotab ${ }^{\circledR}$, changes are seen in lower intensity of stretching vibrations from 1000 to $1500 \mathrm{~cm}^{-1}$. No new peaks, or disappearance of the drug original peaks, were observed in any of the binary mixtures. Hence, a compatibility study could speculate that risperidone combinations tested are binary physical mixtures with no drug degradation.

\section{Feasibility of risperidone loaded OD-mini-tablets for pediatric patients}

The preparation of OD-mini-tablets incorporating risperidone by direct compression was a complex physical process with no evidences of drug interactions. All of the excipient combinations possessed fair flowability, and mannitol to Avicel diluent mixture $(6: 4, \mathrm{~m} / \mathrm{m})$ showed the best results. The powder blend should have acceptable compaction properties in order to employ a low compression force to prepare OD-mini-tablets with acceptable hardness and low friability. The optimized formulation fulfilled these requirements by having a crushing strength of $5 \mathrm{kN}$ and minimal friability. Another feature particularly important for pediatric application, was the short disintegration times as indicators of fast disintegration both on the tongue and in a feeding bottle with skimmed milk formula. The optimized formulation fulfilled these requirements by having disintegration times of 8.4 and $53.7 \mathrm{~s}$ in SSF and skimmed milk, respectively. Therefore, this optimized risperidone loaded OD-mini-tablet formula provides a ready-to-use excipient combination for pediatric population.

\section{CONCLUSIONS}

In the present study, an experimental Box-Behnken design was used to assess the formulation variables in an attempt to find the most suitable excipient combination in the preparation of risperidone as an OD-mini-tablet with minimum variability. Statistical optimization revealed a successful formulation with $2 \mathrm{~mm}$ diameter, acceptable mechanical strength, minimal friability, uniformity of mass and drug content and short disintegration time. Based on these promising results, the optimized OD-mini-tablet formula will contribute the development of a novel dosage form suitable for pediatric use.

\section{REFERENCES}

1. P. Lennartz and J. B. Mielck, Minitabletting: Improving the compactability of paracetamol powder mixtures, Int. J. Pharm. 173 (1998) 75-85; DOI: 10.1016/S0378-5173(98)00206-3.

2. I. Stoltenberg and J. Breitkreutz, Orally disintegrating mini-tablets (odmts) - a novel solid oral dosage form for paediatric use, Eur. J. Pharm. Biopharm. 78 (2011) 462-469; DOI: 10.1016/j.ejpb. 2011.02.005.

3. K. Wening and J. Breitkreutz, Oral drug delivery in personalized medicine: Unmet needs and novel approaches, Int. J. Pharm. 404 (2011) 1-9; DOI: 10.1016/j.ijpharm.2010.11.001.

4. D. L. Munday, A comparison of the dissolution characteristics of theophylline from film coated granulesand mini-tablets, Drug Dev.Ind.Pharm.20(1994)2369-2379;DOI:10.3109/03639049409042643.

5. M. L. Huang, A. Van Peer, R. Woestenborghs, R. De Coster, J. Heykants, A. A. Jansen, Z. Zylicz, H. W. Visscher and J. H. Jonkman, Pharmacokinetics of the novel antipsychotic agent risperidone 
and the prolactin response in healthy subjects, Clin. Pharmacol. Ther. 54 (1993) 257-268; DOI: 10.1038/clpt.1993.146.

6. ICH(Q4b) Guideline, General chapters, Annex 6, Step 4. Evaluation and recommendation of pharmacopeial texts for use in the ICH regions on uniformity of dosage units, in: Group, I.E.W. (ed.), ICH Harmonised Tripartite Guideline J.FDA, EMA, US. FDA, USA. 2014; Available from: http:// www.ich.org/fileadmin/Public_Web_Site/ICH_Products/Guidelines/Quality/Q4B/Step4/Q4B_ Guideline.pdf; last access date July 23, 2015.

7. S. Khan, P. Kataria, P. Nakhat and P. Yeole, Taste masking of ondansetron hydrochloride by polymer carrier system and formulation of rapid-disintegrating tablets, AAPS PharmSciTech. 8 (2007) E127-E133; DOI: 10.1208/pt0802046.

8. I. Mutlu and E. Oktay, Characterization of 17-4 PH stainless steel foam for biomedical applications in simulated body fluid and artificial saliva environments, Mater. Sci. Eng. C, Mater. Biol. Appl. 33 (2013) 1125-1131; DOI: 10.1016/j.msec.2012.12.004.

9. J. S. P. Daniel, I. P. Veronez, L. L. Rodrigues, M. G. Trevisan and J. S. Garcia, Risperidone - solidstate characterization and pharmaceutical compatibility using thermal and non-thermal techniques, Thermochim. Acta 568 (2013) 148-155; DOI: 10.1016/j.tca.2013.06.032.

10. R. Canitano and V. Scandurra, Risperidone in the treatment of behavioral disorders associated with autism in children and adolescents, Neuropsychiatr. Dis. Treat. 4 (2008) 723-730; DOI: 10.2147/ NDT.S1450.

11. C. C. Sun, Mechanism of moisture induced variations in true density and compaction properties of microcrystalline cellulose, Int. J. Pharm. 346 (2008) 93-101; DOI: 10.1016/j.jpharm.2007.06.017.

12. J. G. Osorio and F. J. Muzzio, Effects of powder flow properties on capsule filling weight uniformity, Drug Dev. Ind. Pharm. 39 (2013) 1464-1475; DOI: 10.3109/03639045.2012.728227.

13. D. Otter, Milk: Physical and Chemical Properties, in Encyclopedia of Food Sciences and Nutrition (Ed. B. Caballero, L. C. Trugo, P. M. Finglas), 2nd ed., Academic Press, Oxford 2003, pp. 3957-3963.

14. M. B. Almeida, J. A. Almeida, M. E. Moreira and F. R. Novak, Adequacy of human milk viscosity to respond to infants with dysphagia: Experimental study, J. Appl. Oral Sci. 19 (2011) 554-559; DOI: 10.1590/S1678-77572011000600003.

15. W.H.Schwarz,Therheology of saliva,J.Dent.Res. 66(1987)660-666;DOI:10.1177/00220345870660S209.

16. R. Pabari and Z. Ramtoola, Effect of a disintegration mechanism on wetting, water absorption, and disintegration time of orodispersible tablets, J. Young Pharm. 4 (2012) 157-163; DOI: 10.4103/09751483.100021.

17. A. M. Juppo, Relationship between breaking force and pore structure of lactose, glucose and mannitol tablets, Int. J. Pharm. 127 (1996) 95-102; DOI: 10.1016/0378-5173(95)04203-2. 